\title{
Lingual Radicular Rift Valley in a Mandibular Right First Premolar Root: Report of a Rare Case and Review of the Literature
}

\author{
Surco Radicular Lingual en la Raíces del Primer Premolar Mandibular Derecho: \\ Reporte de un Raro Caso y Revisión de la Literatura
}

\author{
Xiao Hong*; Ru Zhang**; Hongying Pan*; Wanmei Zhang*** \& Tao Hu*
}

HONG, X.; ZHANG, R.; PAN, H. Y.; ZHANG, W. M. \&HU, T. Lingual radicular Rift Valley in a mandibular right first premolar root: Report of a rare case and review of the literature. Int. J. Morphol., 31(1):338-344, 2013.

SUMMARY: Irregular root configurations which often challenge the requirements of successful root canal treatments are always misleading doctors to incorrect clinical judgments and treatment planning. In this article we describe a rare case of CBCT C-shaped mandibular premolar with a huge area of invagination measuring $6 \mathrm{~mm}$ ' $3 \mathrm{~mm}$, which we termed a "radicular rift valley" from a 76-year-old man. Considering the complex process of differential diagnosis, the overall status of disease condition and the will of the patient we proposed five treatment plans and finally conservatively chose plan B composed of both RCT and periapical scaling. A related literature review is also added into this article to describe the whole situation of root invagination, to stress the importance of the vigilance of diagnosis and to provide reference views for future similar diseases.

KEY WORDS: Radicular groove; Premolars; CBCT; Root canal treatment.

\section{INTRODUCTION}

Successful root canal treatment (RCT) requires thorough debridement, sterilization, and three-dimensional (3D) obturation of the entire root canal system. However, such requirements are often challenged by irregular root configurations, which compromise conventional root canal instrumentation and may leave a remnant after debridement, thus increasing the difficulty of RCT (Jerome, 1994; Gutmann \& Rakusin, 1987). Such irregular root configurations have also been reported to directly affect periodontal attachment loss (Bhusari \& Chopra, 2011). Therefore, clinicians must possess a thorough understanding of the conventional root anatomy and its variants, and must be able to make appropriate and skillful adjustments to ensure successful endodontic treatment (Sert \& Bayirli, 2004).

Mandibular first premolars are mostly single-rooted teeth but may also have two roots or more (Sandhya et al., 2010; Iyer et al., 2006; Sikri \& Sikri, 1994; Robinson et al., 2002). In the Chinese population, the incidence of a proximal radicular groove is relatively high $(78.5 \%)$, but that of a lingual radicular groove is only 3.2\% (Ong \& Neo, 1990; Fan et al., 2008).
Usually before beginning RCT, a traditional X-ray examination is required to obtain basic information about the number, shape, and length of the roots and canal systems, and the severity of periapical destruction. Variations in root number or configuration can influence the clinician's interpretation of X-ray films, treatment planning, and prognosis expectations.

This article describes a rare case of root radicular groove with odd X-ray image and opposite cone beam computed tomography (CBCT) result. Five treatment plans are proposed and compared in well-founded way.

\section{CASE REPORT}

The patient was a 76-year-old man. One month before his visit, he had his mandibular right second premolar treated elsewhere because of spontaneous pain in the right mandibular region. The symptoms were alleviated in that tooth, but pain in the mandibular right first premolar

* West China Hospital of Stomatology, State Key Laboratory of Oral Diseases, Sichuan University, Section 3 Chengdu, Sichuan, PR China.

** Department of Endodontics, Capital Medical University School of Stomatology, Beijing, China.

**** Department of Stomatology, The Sixth People's Hospital of Chengdu, Sichuan, PR China. 
worsened. He was referred to the Department of Operative Dentistry, Sichuan University West China Hospital of Stomatology. Physical examination

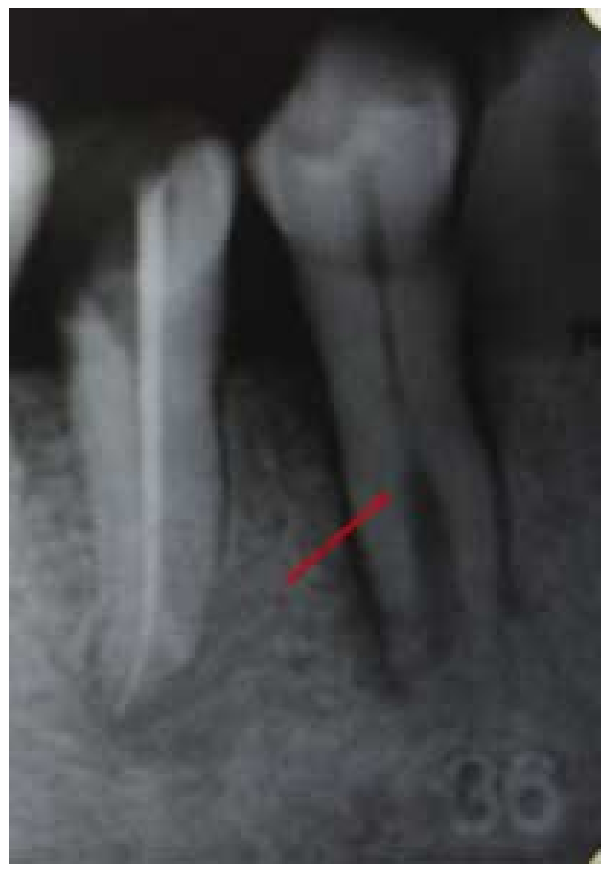

Fig. 1. The clear canal of the mandibular right first premolar stopped suddenly in the middle of the root and through an apparent "root bifurcation" (red arrow), suggesting the presence of a configuration variation in either the root or the canal system.

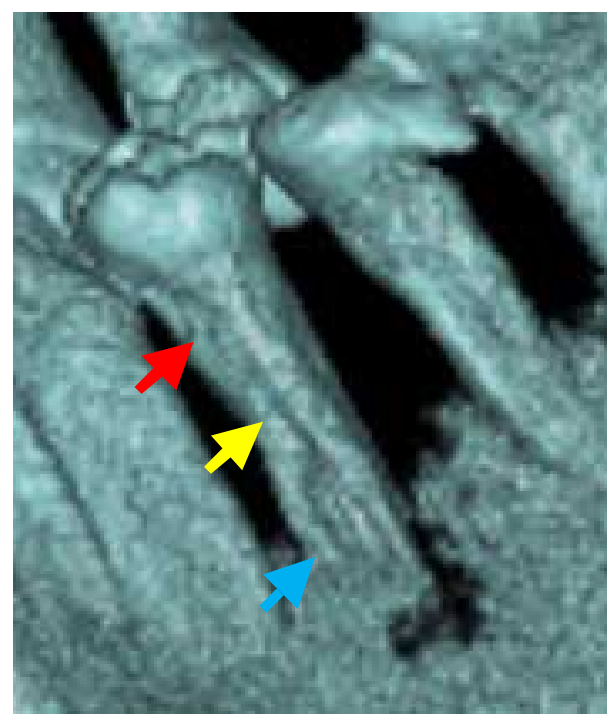

Fig. 2.CBCT 3D reconstruction of the mandibular right first premolar indicating a radicular horizontal groove (red arrow), a vertical groove (yellow arrow), and an enlarged area of radicular invagination (blue arrow). revealed a wedge-shaped defect, which reached only to the level of superficial dentin. The tooth displayed $\mathrm{II}^{\circ}$ of looseness and was very sensitive to percussion. Subsequent X-ray examination revealed an odd finding: the root canal had stopped suddenly in the middle of the root and there seemed to be a root bifurcation in the middle and apical thirds of the root. The area of periodontal destruction surrounded the entire root (Fig. 1).

The clinical diagnosis was chronic periapical periodontitis.

Treatment planning. The tooth was separated with a rubber dam, and the pulp chamber was exposed from the occlusal surface. The infected pulp tissue was removed, and the root canal was probed with a \#10 K-file (Dentsply/Caulk, Dentsply International, Inc., Milford, DE). Only one canal was observed. No other findings were noted using an endodontic microscope.

We questioned the variation of the root configuration. An additional examination was considered, and CBCT was chosen because of its substantial advantages in revealing root configuration variations and in treatment planning, and its ability to provide a rapid volumetric image from a single low-radiation-dose scan (Cheng et al., 2011; Kottoor et al., 2011; Zhang et al., 2011; Kottoor et al., 2010; Huang et al., 2010).

Upon the patient's consent, a CBCT (Morita, Kyoto, Japan) examination was performed. Both cross-sectional analysis and 3D reconstruction showed an obvious $\mathrm{C}$-shaped root with only one canal, which was located in the middle and only slightly mesial portion of the root. The radicular groove started $4 \mathrm{~mm}$ from the cementoenamel junction (CEJ) and coursed increasingly deeper to $12 \mathrm{~mm}$ apical to the CEJ where there was a huge area of invagination measuring $6 \mathrm{~mm} \times 3 \mathrm{~mm}$, which we termed a "radicular rift valley". The lingual wall of the radicular invagination was extremely thin $(<0.5 \mathrm{~mm}$ at the apex). A distinctive area of periodontal destruction surrounded the entire root, especially in the apical third of the root (Figs. 2 and 3).

Treatment plans available: Five treatment plans were prepared.

Plan A: RCT + periapical scaling and retrograde filling + lingual root surface remodeling.

Plan B: RCT + periapical scaling.

Plan C: only conservative RCT + regular follow-up, although poor prognosis was expected.

Plan D: RCT + periapical scaling + lingual root surface remodeling and MTA filling.

Plan E: extraction.

After thorough consideration of the patient's overall status and in consultation with the patient, we chose plan B. The bases for comparison and consideration of these plans are illustrated in detail in discussion part. 

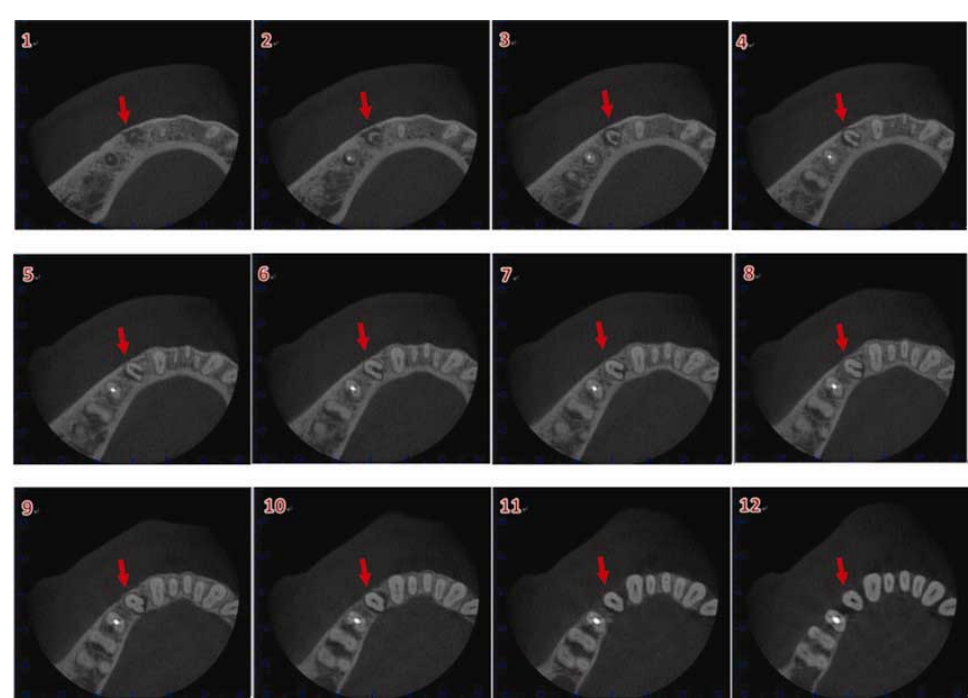

Fig. 3. CBCT multilayer cross-sections show a large area of invagination at the apical third of the root and a shallow radicular groove at the coronal third of the root. Red arrow points at the mandibular right first premolar.

The root canal was prepared using the crown-down technique using the K3 system (Sybron Endo, Orange, CA) from \#25 conicity to \#.04 taper with the help of EDTA gel (Glyde, Maillefer, Dentsply, Ballaigues, Switzerland) and an apex locator (Raypex 5, VDW, Munich, Germany). The canal was irrigated with a large volume of $1 \%$ sodium hypochlorite solution $(\mathrm{NaClO})$, and the endodontic microscopic examination was repeated, but no extra canal was found. A \#25 taper 04 gutta-percha point was inserted into the canal to confirm the working length of the canal preparation (Fig. 4).

The canal was next dried with sterile paper points and then sterilized with calcium hydroxide and $2 \%$ chlorhexidine. The patient attended our department several times. Only when the symptoms had disappeared did we fill the canal with gutta-percha points and AH Plus (DeTrey, Dentsply) using the lateral-condensation technique.
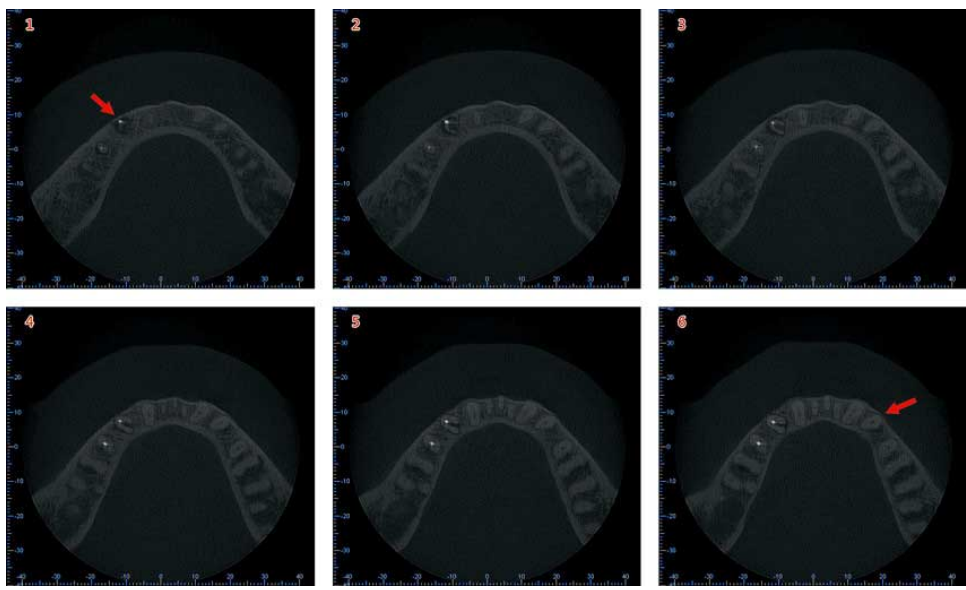

Fig. 5. CBCT examination after RCT shows satisfactory canal filling of the mandibular right first premolar (first red arrow) and a mandibular left first premolar with a normal anatomy last red arrow.

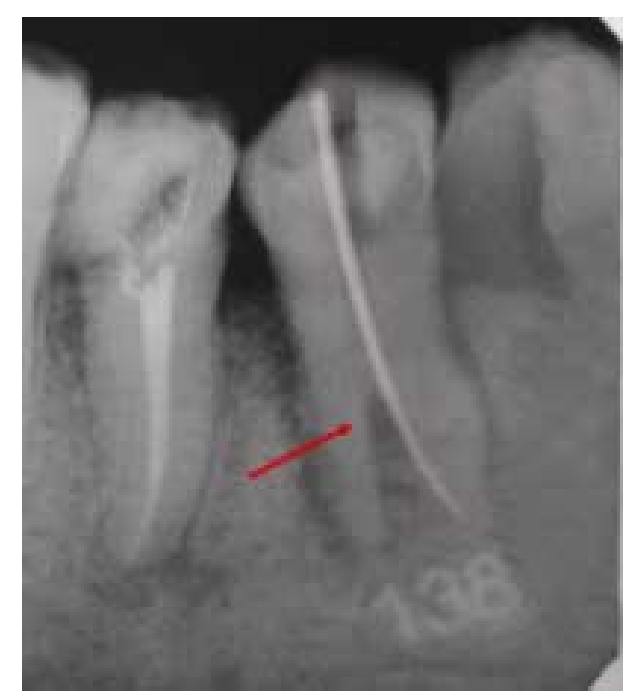

Fig. 4.Use of a gutta-percha point to test the length of the canal preparation.

A second CBCT examination was performed and revealed satisfactory root canal filling and no other canals within the root (Fig. 5). Periapical scaling was then performed.

The patient was followed for 3 months. No symptoms were present, the tooth was? loose, but the shade surrounding the root did not change.

\section{DISCUSSION}

There are several unique aspects of this case. First, the radicular groove started almost from the CEJ but enlarged rapidly into a termed "valley" in the radicular third of the root. Valley in this article means that a huge radicular groove in a C-shaped root forms a deep area of space observed like a "valley" in morphology. Second, the mesial and distal walls of the root were relatively thick, but were extremely thin in the buccal part. Thus, the X-ray film showed that the shape of the canal stopped suddenly and seemed to continue through an apparent yet misleading "root bifurcation". Third, further examination with an endodontic microscope and CBCT yielded no new findings and confirmed the presence of a single canal within the root.

Yoshioka et al. (2004) analyzed the X-ray findings of 139 mandibular premolars and noted that the sudden shrinkage of the root canal is a 
reliable sign for canal system variations. Abnormal radiographic findings may also indicate variations in root configurations besides the canal system.

Reports of radicular grooves are rare, and this abnormality is observed more often in maxillary premolars and mandibular second premolars than in maxillary incisors and mandibular first premolars. Tamse et al., (2000) examined maxillary premolars with two roots and found that $97 \%$ of the teeth had renal invaginations on the buccal root. These invaginations usually started $1.18 \mathrm{~mm}$ apical to the root bifurcation and were on average $5.38 \mathrm{~mm}$ long and 0.40 $\mathrm{mm}$ deep. The larger the root and the more coronal its location, the deeper the radicular invagination. Joseph et al., (1996) found that these invaginations occurred in $62 \%$ of their study sample and were on average $0.46 \mathrm{~mm}$ deep.

Fan et al., (2004) studied 58 mandibular second molars with a fused root and found that $39.7 \%$ had only one lingual radicular groove and that the remaining $60.3 \%$ had both a buccal and a lingual groove. Kogon (1986) reported a $4.6 \%$ incidence of palatal radicular groove in maxillary incisors. Unfortunately, the data were not available for buccal grooves in maxillary incisors but three cases have been reported (Goon et al., 1991; Kerezoudis et al., 2003; Kozlovsky et al., 1988). Robinson et al., found that only 9\% of the ex vivo mandibular first premolars had mesial radicular invaginations.

Cleghorn et al., (2001) summarized the configuration of $>6700$ mandibular first premolars, of which approximately $98 \%$ were single rooted, $1.8 \%$ were double rooted, $0.2 \%$ had three roots, and less than $0.1 \%$ had four roots. In the other 20 teeth with variations in the root or canal system, no deep radicular groove was observed.

Fan et al., (2008) analyzed the size of the radicular groove of C-shaped roots in mandibular first premolars with microcomputed tomography (mCT) and found an average length of $8.77 \mathrm{~mm}$ and depth of $1.44 \mathrm{~mm}$; the total range of depth was $0.39-3.23 \mathrm{~mm}$. The site of maximum radicular concavity was located $5.41 \mathrm{~mm}$ coronal to the apex. Lu et al., (2006) reported that the radicular groove of the mandibular first premolar with a C-shaped root is usually located mesially and slightly lingually on the root surface and originates in the apical $3 \mathrm{~mm}$ and/or $6 \mathrm{~mm}$ level crosssection in their coronal sections, but the groove did not reach the apex.

In this present case, $\mathrm{CBCT}$ cross-sectional analysis and $3 \mathrm{D}$ reconstruction showed that the lingual radicular groove started from $4 \mathrm{~mm}$ apical to the CEJ. It first extended horizontally for $3 \mathrm{~mm}$ then turned at a right angle and continued $8 \mathrm{~mm}$, after which it swelled into the shape of a "rift valley" measuring $6 \mathrm{~mm}{ }^{\prime} 3 \mathrm{~mm}$. This root surface abnormality has not been reported, and we termed it a "radicular rift valley". The rift valley produced the clear Cshaped root morphology in CBCT 3D reconstruction, the deepest part of which was located $5 \mathrm{~mm}$ coronal to the apex (i.e., $3 \mathrm{~mm}$ deep). Because the tooth had a normal counterpart in the left mandible, we considered that the contributing factor of this tooth abnormality was not developmental.

In Asia, the incidence of root configuration variations in mandibular first premolars is relatively high, and the Cshaped root is one of the most frequent variations (Cleghorn et al.; Cooke \& Cox, 1979; Jafarzadeh \& Wu, 2001). It has been reported the incidence of C-shaped roots as $14 \%, 10 \%$, $18 \%$, and 24\%, respectively (Sikri \& Sikri; Fan et al., 2008; Lu et al.; Baisden et al., 1992), and the incidence of only one canal within the C-shaped root was $1.87 \%$ (Baisden $e t$ al.; Weine, 1989).

Fan et al. (2008) developed a modified six-category classification system to describe the root canal system of Cshaped roots. In our case, the radicular groove started from the coronal third of the root and formed a C-shape in CBCT cross-section. There was a single canal in the root, and the long and short diameters were almost equal (Fig. 3, parts 811). This root falls within category $\mathrm{C} 4 \mathrm{a}$ of the classification system of Fan et al. However, in the middle third of the root, the radicular groove began to deepen and eventually formed a deep and wide area, which appeared as an extremely clear C-shape with a single canal in the middle (Fig. 3, parts $3-8)$. This root morphology cannot be ascribed to any classification category.

This abnormal root and canal anatomy presents extra difficulties in controlling inflammation, debridement, and shaping of the root canal. In the study of Chai \& Thong (2004) at the site of the radicular groove, the C-shaped root had a canal with reduced mean wall thickness of $0.96 \pm$ $0.26 \mathrm{~mm}$ on the buccal side and $0.58 \pm 0.21 \mathrm{~mm}$ on the lingual side, indicating an area of isthmus that could be endangered during RCT (Jerome; Chai \& Thong; Gao et al., 2006). Sandhya et al., measured the canal wall thickness of mandibular first premolars with mesial invagination and found average thicknesses of the walls of $0.8 \mathrm{~mm}$ in the coronal third, $0.78 \mathrm{~mm}$ in the middle third and only 0.3 $\mathrm{mm}$ in the apical third. In the present case, the cross-sections of the root showed a very clear C-shape, and the root canal was located in the middle. Therefore, the canal wall at the site of maximum root concavity was so thin that special care was needed during the root canal instrumentation because over-preparation could have caused root perforation, especially at the fragile site of the $\mathrm{C}$-shaped 
invagination. We advise that in such cases of a radicular groove or rift valley, the extent and location of the canal must be profiled clearly to measure the canal diameter, and instrumentation and cutting at the side of the invagination should be minimal to avoid perforation.

In our patient, CBCT multilayer cross-sections showed that the $\mathrm{C}$-shaped root rift valley was accompanied by an area of alveolar bone defect. Thus, periapical inflammation could be controlled only with RCT to the single canal. We suggested four treatment plans to the patient. Plan A was thought to be the most thorough, but retrograde filling might have caused the following problems. First, because the area of both the gingival fistula and alveolar bone destruction were located in the buccal part of the mandible, an operation from the lingual side was very difficult and would cause more alveolar bone destruction. Second, the huge radicular rift valley was located at the apex, and retrograde filling would have had to be performed coronal to it, which would have inevitably increased the crown-root ratio and severely reduced masticatory support. Third, the alveolar bone repair would have been poor because of the patient's age. Plan B was thought to be more feasible because it combined root canal treatment and periapical scaling. This was advantageous because it would have produced a smaller wound and better treatment of the periapical inflammation, and would have been tolerated better by the patient. However, the area of inflammation at the radicular rift valley could not be reached by scaling, and the long-term prognosis of this tooth was deemed poor. Plan C was not considered a good plan because RCT alone was insufficient to resolve this complicated condition, Plan D focus on MTA closed root surface defects place and induction of surrounding bone tissue regeneration and plan $\mathrm{E}$ was considered to be the last resort.

Most patients want to participate in making the decision about the treatment strategy, and the two main tasks for the clinician lie in offering different available treatment plans and instruction about the selection process instead of choosing the best plan irrespective of the patient's wishes (Hayes-Bautista, 1976; Nease et al., 1995; Deber et al., 1996). In other words, clinicians must adjust their treatment plans accordingly.

After thorough consideration of the patient's overall health status, the clinical situation of the target tooth, the cost, and the patient's preference, we agreed on the second treatment plan B. However maybe plan D is easy repair methods relating tooth surface defect and the surrounding bone tissue engineering in the future.

\section{ACKNOWLEDGEMENTS}

This work was supported by the Key Clinical Program of the Ministry of Health of China. The funding body had no role in the study design, data collection and analysis, decision to publish, or preparation of the manuscript.

HONG, X.; ZHANG, R.; PAN, H. Y.; ZHANG, W. M. \&HU, T. Surco radicular lingual en la raíces del primer premolar mandibular derecho: Reporte de un raro caso y revisión de la literatura. Int. J. Morphol., 31(1):338-344, 2013.

RESUMEN: Las configuraciones radiculares irregulares que a menudo desafían las exigencias de un tratamiento de canal radicular exitoso, son siempre engañosas llevando al especialista a juicios clínicos y planificación de tratamientos erróneos. En este artículo se describe, en un hombre de 76 años de edad, un raro caso de un premolar mandibular que mediante CBCT se observa la forma de $\mathrm{C}$ con un área enorme de invaginación midiendo $6 \mathrm{~mm}$ x $3 \mathrm{~mm}$, lo que hemos denominado un "Rift valley radicular ". Teniendo en cuenta el complejo proceso de diagnóstico diferencial, el estado general de enfermedad y la voluntad del paciente, se propusieron cinco planes de tratamiento y, finalmente, se eligió el plan B conservador compuesto por el tratamiento del canal radicular y tratamiento periapical. Una revisión de la literatura relacionada se añade en este artículo para describir las situación de invaginación radicular, haciendo hincapié en la importancia del diagnóstico y para proporcionar referencias para enfermedades similares futuras.

PALABRAS CLAVE: Fisura radicular; Premolares; CBCT, Tratamiento de canal radicular.

\section{REFERENCES}

Baisden, M. K.; Kulild, J. C. \& Weller, R. N. Root canal configuration of the mandibular first premolar. J. Endod., 18(10):505-8, 1992.
Bhusari, P. A. \& Chopra, R. A morphological survey of root grooves and their influence on periodontal attachment loss. Saudi Dent. $J ., 23(2): 91-7,2011$. 
Chai, W. L. \& Thong, Y. L. Cross-sectional morphology and minimum canal wall widths in C-shaped roots of mandibular molars. J. Endod., 30(7):509-12, 2004.

Cheng, L.; Zhang, R.; Yu, X.; Tian, Y.; Wang, H.; Zheng, G. \& $\mathrm{Hu}, \mathrm{T}$. A comparative analysis of periapical radiography and cone-beam computerized tomography for the evaluation of endodontic obturation length. Oral Surg., Oral Med., Oral Pathol., Oral Radiol. Endod., 112(3):383-9, 2011.

Cleghorn, B. M.; Christie, W. H. \& Dong, C. C. S. The root and root canal morphology of the human mandibular first premolar: a literature review. J. Endod., 33(5):509-16, 2001.

Cooke, H. G. 3rd. \& Cox, F. L. C-shaped canal configurations in mandibular molars. J. Am. Dent. Assoc., 99(5):836-9, 1979.

Deber, R. B.; Kraetschmer, N. \& Irvine, J. What role do patients wish to play in treatment decision making? Arch. Intern. Med., 156(13):1414-20, 1996.

Fan, B.; Cheung, G. S. P.; Fan, M. W.; Gutmann, J. L. \& Bian, Z. C-shaped canal system in mandibular second molars: Part I-anatomical features. J. Endod., 30(12):899-903, 2004.

Fan, B.; Yang, J.; Gutmann, J. L. \& Fan, M. W. Root canal systems in mandibular first premolars with C-shaped root configurations. Part I: Microcomputed tomography mapping of the radicular groove and associated root canal crosssections. J. Endod., 34(11):1337-41, 2008.

Gao, Y.; Fan, B.; Cheung, G. S.; Gutmann, J. L. \& Fan, M.W. $\mathrm{C}$-shaped canal system in mandibular second molars part IV: 3-D morphological analysis and transverse measurement. J. Endod., 32(11):1062-5, 2006.

Goon, W. W.; Carpenter, W. M.; Brace, N. M. \& Ahlfeld, R. J. Complex facial radicular groove in a maxillary lateral incisor. J. Endod., 17(5):244-8, 1991.

Gutmann, J. L. \& Rakusin, H. Perspectives on root canal obturation with thermoplasticized injectable gutta-percha. J. Int. Endod., 20(6):261-70, 1987.

Hayes-Bautista, D. E. Modifying the treatment: patient compliance, patient control and medical care. Soc. Sci. Med., 10(5):233-8, 1976.

Huang, C. C.; Chang, Y. C.; Chuang, M. C.; Lai, T. M.; Lai, J. Y.; Lee, B. S. \& Lin, C.P. Evaluation of root and canal systems of mandibular first molars in Taiwanese individuals using cone-beam computed tomography. J. Formos. Med. Assoc., 109(4):303-8, 2010.

Iyer, V. H.; Indira, R.; Ramachandran, S. \& Srinivasan, M. R. Anatomical variations of mandibular premolars in Chennai population. Indian J. Dent. Res., 17(1):7-10, 2006.
Jafarzadeh, H. \& Wu, Y. N. The C-shaped root canal configuration: a review. J. Endod., 33(5):517-23, 2001.

Jerome, C. E. C-shaped root canal systems: diagnosis, treatment, and restoration. Gen. Dent., 42(5):424-7, 1994.

Joseph, I.; Varma, B. R. \& Bhat, K. M. Clinical significance of furcation anatomy of the maxillary first premolar: a biometric study on extracted teeth. J. Periodontol., 67(4):386-9, 1996.

Kerezoudis, N. P.; Siskos, G. J. \& Tsatsas, V. Bilateral buccal radicular groove in maxillary incisors: case report. Int. Endod. J., 36(12):898-906, 2003.

Kogon, S. L. The prevalence, location and conformation of palatoradicular grooves in maxillary incisors. J. Periodontol., 57(4):231-4, 1986.

Kottoor, J.; Hemamalathi, S.; Sudha, R. \& Velmurugan, N. Maxillary second molar with 5 roots and 5 canals evaluated using cone beam computerized tomography: a case report. Oral Surg. Oral Med. Oral Pathol. Oral Radiol. Endod., 109(2):e162-5, 2010.

Kottoor, J.; Velmurugan, N.; Ballal, S. \& Roy, A. Four-rooted maxillary first molar having C-shaped palatal root canal morphology evaluated using cone-beam computerized tomography: a case report. Oral Surg. Oral Med. Oral Pathol. Oral Radiol. Endod., 111(5):e41-5, 2011.

Kozlovsky, A.; Tal, H.; Yechezkiely, N. \& Mozes, O. Facial radicular groove in a maxillary central incisor. A case report. J. Periodontol., 59(9):615-7, 1988.

Lu, T.; Yang, S. F. \& Pai, S. F. Complicated root canal morphology of mandibular first premolar in a Chinese population using the cross section method. J. Endod.,32(10):932-6, 2006.

Nease, R. F. Jr. \& Brooks, W. B. Patient desire for information and decision making in health care decisions. J. Gen. Intern. Med., 10(11):593-600, 1995.

Ong, G. \& Neo, J. A survey of approximal root concavities in an ethnic Chinese population. Arch. Oral Biol., 35(11):925-8, 1990.

Robinson, S.; Czerny, C.; Gahleitner, A.; Bernhart, T. \& Kainberger, F. M. Dental CT evaluation of mandibular first premolar root configurations and canal variations. Oral Surg. Oral Med. Oral Pathol. Oral Radiol. Endod., 93(3):328-32, 2002.

Sandhya, R.; Velmurugan, N. \& Kandaswamy, D. Assessment of root canal morphology of mandibular first premolars in the Indian population using spiral computed tomography: an in vitro study. Indian J. Dent. Res., 21(2):169-73, 2010.

Sert, S. \& Bayirli, G.S. Evaluation of the root canal configuration of the mandibular and maxillary permanent teeth by gender in Turkish population. J. Endod., 30(6):391-8, 2004. 
HONG, X.; ZHANG, R.; PAN, H. Y.; ZHANG, W. M. \&HU, T. Lingual radicular Rift Valley in a mandibular right first premolar root: Report of a rare case and review of the literature. Int. J. Morphol., 31(1):338-344, 2013.

Sikri, V. K. \& Sikri, P. Mandibular premolars aberrations in pulp space morphology. Indian J. Dental Res., 5(1):9-14, 1994.

Tamse, A.; Katz, A. \& Pilo, R. Furcation groove of buccal root of maxillary first premolars-a morphometric study. J. Endod., 26(6):359-63, 2000.

Weine, F. S. Endodontic therapy. $4^{\text {th }}$ ed. St. Louis, CV Mosby, 1989. pp.222-3.

Yoshioka, T.; Villegas, J. C.; Kobayashi, C. \& Suda, H. Radiographic evaluation of root canal multiplicity in mandibular first premolars. J. Endod., 30(2):73-4, 2004.

Zhang, R.; Wang, H.; Tian, Y. Y.; Yu, X. \& Hu, T. Use of conebeam computed tomography to evaluate root and canal morphology of mandibular molars in Chinese individuals. Int. Endod. J., 44(11):990-9, 2011.
Correspondence to:

$\mathrm{Tao} \mathrm{Hu}$

State Key Laboratory of Oral Diseases

West China Hospital of Stomatology

Sichuan University

14 South Renmin Road

Section 3, Chengdu

Sichuan, 610041

PR CHINA

Phone: +86(0)28 85502415

Fax: $\quad+86(0) 2885582167$

Email: acomnet@263.net

Received: 12-07-2012

Accepted: 24-09-2012 